\title{
Biochemical and Immunochemical Study of Seven Families with 3-Ketothiolase Deficiency: Diagnosis of Heterozygotes Using Immunochemical Determination of the Ratio of Mitochondrial Acetoacetyl-CoA Thiolase and 3-Ketoacyl-CoA Thiolase Proteins
}

\author{
SEIJI YAMAGUCHI, ATSUKO SAKAI, TOSHIYUKI FUKAO, AKIHIRO WAKAZONO, \\ TAKASHI KUWAHARA, TADAO ORII, AND TAKASHI HASHIMOTO
}

Department of Pediatrics, Gifu University School of Medicine [S.Y., A.S., T.F., A.W., T.K., T.O.], Gifu 500, Japan; and Department of Biochemistry, Shinshu University School of Medicine [T.H.], Matsumoto, Nagano 390, Japan

\begin{abstract}
The possibility of identifying heterozygotes of 3-ketothiolase deficiency, an inborn error of metabolism caused by a defect of mitochondrial acetoacetyl-CoA thiolase (T2), was tested in seven unrelated families by using enzymatic assay of thiolase activity and immunoblot analysis. The ratio of acetoacetyl-CoA thiolase activities, in the presence and absence of $\mathrm{K}^{+}$ion $(+K /-K$ ratio), in fibroblasts from 15 normal controls was around 2.0 (1.8 to 2.4), whereas the $+K /-K$ ratio in eight patients was always 1.0 . The ratio for the 13 obligate carriers ranged from 1.4 to 1.9, causing a minor overlap with control. Identification of heterozygote cells by immunoblot analysis, using anti-T2 antibody alone as a probe, was difficult, as previously reported. We therefore carried out immunoblot analysis, using as probes a mixture of anti-T2 antibody and the antibody against mitochondrial 3-ketoacyl-CoA thiolase (T1), another mitochondrial thiolase, and determined the ratio of the intensities of the $\mathrm{T} 2$ and $\mathrm{T} 1$ bands $(\mathrm{T} 2 / \mathrm{T} 1$ ratio) using a densitometer. When the $\mathrm{T} 2 / \mathrm{T} 1$ ratio was calculated, there was no overlap between the heterozygotes and normal controls. Hence, the heterozygotes can be unambiguously identified using this method. The thiolase activities and T2/T1 proteins in immunoblotting were detectable in peripheral lymphocytes, rectal mucosa, amniocytes, and liver. Thus, the postnatal diagnosis of 3-ketothiolase deficiency can be readily made using lymphocytes or rectal mucosa. The applicability of these methods in amniocytes indicates that prenatal diagnosis of this disease should be possible. (Pediatr Res 33: 429-432, 1993)
\end{abstract}

\section{Abbreviations}

3KTD, 3-ketothiolase deficiency

$+K$, acetoacetyl-CoA thiolase activity in the presence of $\mathrm{K}^{+}$ion

$-\mathrm{K}$, acetoacetyl-CoA thiolase activity in the absence of $\mathrm{K}^{+}$ ion

Received June 8, 1992; accepted January 13, 1993.

Correspondence: Seiji Yamaguchi, M.D., Department of Pediatrics, Gifu University School of Medicine, 40 Tsukasa-machi, Gifu 500, Japan.

Supported in part by grants from the National Center of Neurology and Psychiatry of the Ministry of Health and Welfare of Japan (2A-6-01 and 2A-11-19) and for Pediatric Research (63-A) from the Ministry of Health and Welfare of Japan.
T2, mitochondrial acetoacetyl-CoA thiolase T1, mitochondrial 3-ketoacyl-CoA thiolase

$3 \mathrm{KTD}$ is an inherited metabolic disorder of isoleucine and ketone body catabolism (1-3), caused by a defect of T2 (4). It is an autosomal recessive disease. The clinical expression of $3 \mathrm{KTD}$ is highly variable. Typical manifestations are severe ketoacidosis and excessive excretion of 2-methyl-3-hydroxybutyrate, 2-methylacetoacetate, and tiglylglycine in urine. However, many patients with $3 \mathrm{KTD}$ have no symptoms other than the occurrence of episodic ketoacidosis in childhood (3). On the other hand, some patients may develop chronic neurologic symptoms such as mental retardation, hypotonia, or gait disturbance as sequelae after severe ketoacidotic attacks $(5,6)$. Early detection and treatment of this disorder are important, because patients with 3KTD may achieve normal development with early intervention. Hence, it will be useful to develop simple and reliable methods for carrier detection and prenatal diagnosis.

In addition to $\mathrm{T} 2$, four other thiolases are currently known in mammals $(7,8)$. These include $\mathrm{T} 1$, peroxisomal 3-ketoacyl-CoA thiolase, cytosolic acetoacetyl-CoA thiolase, and mitochondrial trifunctional protein. Of the five thiolases, all have acetoacetylCoA thiolase activity, except for the mitochondrial trifunctional protein (8), although the specific activities do vary. However, only $\mathrm{T} 2$ possesses the peculiar property that its activity is enhanced by $\mathrm{K}^{+}$ion when assayed with acetoacetyl-CoA as substrate (9). Accordingly, acetoacetyl-CoA thiolase activity in tissues from patients with $3 \mathrm{KTD}$ is not activated by $\mathrm{K}^{+}$ion $(10)$, whereas in normal controls the activity is increased to about double that in the absence of $\mathrm{K}^{+}$ion

We have extensively studied the molecular basis of $3 \mathrm{KTD}$. In our previous study of 15 cases of 3KTD using cultured skin fibroblasts, no increase of the acetoacetyl-CoA thiolase activity in cells from all the patients by $\mathrm{K}^{+}$ion was observed. When analyzed with immunoblot, $\mathrm{T} 2$ protein in cells from patients with 3KTD was undetectable or the intensity of the variant T2 band was extremely reduced $(11-13)$. However, T2 protein in 10 of 15 patients was efficiently labeled in a pulse-labeling experiment using $\left[{ }^{35} \mathrm{~S}\right]$ methionine, suggesting $\mathrm{T} 2$ in these mutant cells was synthesized (13). Thus, variant T2 appears to be unstable. In the recent sequence analysis, we have identified six mutations, 
within the T2 gene of four cases, that are responsible for this 3KTD deficiency. Each of these different mutations, except one, produced a labile variant $T 2$ protein that was undetectable with immunoblot analysis (14-18).

Family studies have also been performed in some cases. In a thiolase assay of three families, the ratio of acetoacetyl-CoA thiolase activities in the presence and absence of $\mathrm{K}^{+}(+\mathrm{K} /-\mathrm{K}$ ratio) seemed to be rather low in obligatory carriers compared with that in normal controls $(19,20)$. It was difficult to identify unequivocally heterozygotes when immunoblot analysis was performed using anti-T2 antibody alone (11). However, we observed that the identification of carriers could be convincingly achieved by performing immunoblot analysis using a mixture of anti-T2 and anti-T1 antibodies, with the $\mathrm{T} 1$ band serving as an internal standard $(15,16,19,20)$.

We report here the identification of homozygotes and obligate heterozygotes of 3KTD deficiency in three unreported families as well as four previously examined families by using thiolase assay and immunoblot analysis of fibroblasts, and, in one family, lymphocytes and rectal mucosa, as well. Distribution of T2 in several other human tissues was also examined using these two methods. The results from this study confirm the usefulness of immunoblot analysis using the mixture of anti-T2 and anti-T1 antibodies as a probe for the identification of heterozygotes and for a prenatal diagnosis as well.

\section{MATERIALS AND METHODS}

Materials. Fibroblasts obtained from eight patients with $3 \mathrm{KTD}$ (GK01, GK04, GK05, GK06, GK07, GK10, GK12, and GK15) and the parents from the seven families and 15 normal controls were cultured in Eagle's minimum essential medium containing $10 \% \mathrm{FCS}(\mathrm{vol} / \mathrm{vol})$. Fibroblasts from 3KTD patients and their parents, obligate heterozygotes, were provided as follows: family 1 of GK01 were from Dr. N. Sakura, Hiroshima University, Japan (21); family 2 of GK04 and GK05, a son and father who are both affected, from Dr. R. B. H. Schutgens, University Hospital, Amsterdam, The Netherlands (22); family 3 of GK06 from Dr. G. Frauendienst-Egger, Wurzburg University, Germany (15); family 4 of GK07 from Dr. G. Hoganson, University of Illinois, Chicago; family 5 of GK 10 from Dr. D. A. Applegarth, British Columbia's Children's Hospital, Vancouver, Canada (16); family 6 of GK 12 from Dr. M. Wajner, Hospital de Clinicas de Porto Alegre, Brazil (19); and family 7 of GK 15 from Dr. D. T. Whelan, McMaster University, Hamilton, Ontario, Canada. Peripheral lymphocytes were prepared from heparinized venous blood from GK01, the father, and the mother, as well as six healthy volunteers, on a Ficoll-sodium metrizoate gradient (Nakarai Chemical Ltd., Tokyo, Japan). Amniocytes were obtained by amniocentesis performed at the 16 th to 20 th wk of gestation for a prenatal diagnosis of other diseases. Specimens of rectal mucosa were taken from GK01 and five controls: two specimens were biopsied for a diagnosis of other diseases, using Watson's intestinal biopsy capsule (Ferraris Development and Engineering Co. Ltd., London, UK), and three were taken at autopsy on patients with other diseases. Liver specimens were taken at autopsy from six individuals with other diseases, and all tissues were stored at $-80^{\circ} \mathrm{C}$ until analysis.

Enzyme assay. Thiolase activities were measured with acetoacetyl-CoA and 3-ketooctanoyl-CoA as substrates, as described (4). The acetoacetyl-CoA thiolase activity was assayed in the presence and the absence of $\mathrm{K}^{+}$ion, and the $+\mathrm{K} /-\mathrm{K}$ ratio was calculated.

Immunoblot analysis. Antibodies against $\mathrm{T} 1$ and $\mathrm{T} 2$ were prepared as described (7), and immunoblotting was performed by using a mixture of the two antibodies, anti-T1 and anti-T2, as the first antibody, according to the method described elsewhere (4). The intensity of the bands was determined by densitometry, and the ratio of peak areas for $\mathrm{T} 2$ and $\mathrm{T} 1$ bands (T2/T1 ratio) was calculated.

\section{RESULTS}

Thiolase activities in various normal human tissues. Table 1 summarizes thiolase activities, which were determined using acetoacetyl-CoA and 3-ketooctanoyl-CoA as substrates in several tissues, including fibroblasts, lymphocytes, rectal mucosa, amniocytes, and the liver. The specific activity of the thiolases in the normal controls was highest in the liver, followed by rectal mucosa, lymphocytes, fibroblasts, and amniocytes. The activities in fibroblasts and amniocytes appeared to be similar. The $+\mathrm{K} /$ $-\mathrm{K}$ ratio was around 2.0 in all these tissues, although the specific activities did vary among tissues. These findings suggest that the ratio of $\mathrm{T} 2$ to total acetoacetyl-CoA thiolase activity present in cells is similar in all human tissues. The specific activity of 3 ketooctanoyl-CoA thiolase in each tissue appeared to be roughly proportional to that of acetoacetyl-CoA thiolase.

Thiolase activity in cells from index cases, obligate heterozygotes, and controls. Values of the $+\mathrm{K} /-\mathrm{K}$ ratio in fibroblasts from 15 normal controls ranged from 1.8 to 2.4 (mean value, 2.0 ), whereas the ratio was 1.0 in all eight 3 KTD patients. The ratio in the parents ranged from 1.4 to 1.9 (mean, 1.6). The value in the obligate carriers was significantly lower than that in normal controls $(p<0.01)$, but overlaps with controls were observed in three cases $(+\mathrm{K} /-\mathrm{K}, 1.9$ in one case; 1.8 in two cases).

Similarly, the $+\mathrm{K} /-\mathrm{K}$ ratio in both lymphocytes and rectal mucosa from GK01 was also 1.0 , and the $+\mathrm{K} /-\mathrm{K}$ ratio in lymphocytes from the parents of GK01 was 1.5 and 1.3 as shown in Table 1, suggesting that identification of heterozygotes by thiolase assay using lymphocytes as well as fibroblasts may be feasible.

Identification of heterozygotes using immunoblot analysis. Figure 1 shows immunoblots of $\mathrm{T} 1$ and $\mathrm{T} 2$ in fibroblasts from

Table 1. Thiolase activities in human tissues*

\begin{tabular}{|c|c|c|c|c|}
\hline \multirow{2}{*}{ Substrate } & \multicolumn{3}{|c|}{ Acetoacetyl-CoA } & \multirow{2}{*}{$\begin{array}{l}\text { 3-Ketooctanoyl- } \\
\text { CoA }\end{array}$} \\
\hline & $+\mathrm{K}$ & $-\mathrm{K}$ & $+\mathrm{K} /-\mathrm{K}$ & \\
\hline \multicolumn{5}{|l|}{ Fibroblasts } \\
\hline Control $(n=15)$ & $\begin{array}{c}9.1 \\
(6.6-11.9)\end{array}$ & $\begin{array}{c}4.4 \\
(3.2-6.3)\end{array}$ & $\begin{array}{c}2.0 \\
(1.8-2.4)\end{array}$ & $\begin{array}{c}9.8 \\
(6.9-12.9)\end{array}$ \\
\hline Patient $(n=8)$ & $\begin{array}{c}3.3 \\
(2.7-4.0)\end{array}$ & $\begin{array}{c}3.3 \\
(2.7-3.9)\end{array}$ & $\begin{array}{c}1.0 \\
(1.0-1.0)\end{array}$ & $\begin{array}{c}9.1 \\
(7.4-11.7)\end{array}$ \\
\hline Father $(n=6)$ & $\begin{array}{c}5.2 \\
(3.8-7.5)\end{array}$ & $\begin{array}{c}3.1 \\
(2.2-3.9)\end{array}$ & $\begin{array}{c}1.65 \\
(1.4-1.9)\end{array}$ & $\begin{array}{c}9.1 \\
(7.4-9.7)\end{array}$ \\
\hline Mother $(n=7)$ & $\begin{array}{c}5.1 \\
(4.4-6.9)\end{array}$ & $\begin{array}{c}3.1 \\
(2.4-3.7)\end{array}$ & $\begin{array}{c}1.61 \\
(1.4-1.9)\end{array}$ & $\begin{array}{c}9.9 \\
(7.6-12.9)\end{array}$ \\
\hline \multicolumn{5}{|l|}{ Lymphocytes } \\
\hline Control $(n=10)$ & $\begin{array}{c}17.5 \\
(14.2-21.8)\end{array}$ & $\begin{array}{c}8.9 \\
(6.7-10.6)\end{array}$ & $\begin{array}{c}2.0 \\
(1.9-2.4)\end{array}$ & $\begin{array}{c}17.5 \\
(14.5-22.6)\end{array}$ \\
\hline GK01 & 7.5 & 7.5 & 1.0 & 18.1 \\
\hline Father 1 & 14.3 & 9.7 & 1.5 & 13.3 \\
\hline Mother 1 & 10.7 & 8.3 & 1.3 & 12.2 \\
\hline \multicolumn{5}{|l|}{ Rectal mucosa } \\
\hline Control $(n=5)$ & $\begin{array}{c}41.8 \\
(30.4-49.6)\end{array}$ & $\begin{array}{c}19.2 \\
(15.4-24.8)\end{array}$ & $\begin{array}{c}2.1 \\
(2.0-2.3)\end{array}$ & $\begin{array}{c}27.2 \\
(21.4-36.8)\end{array}$ \\
\hline GK01 & 17.2 & 17.2 & 1.0 & 36.5 \\
\hline \multicolumn{5}{|l|}{ Amniocytes } \\
\hline Control $(n=5)$ & $\begin{array}{c}8.9 \\
(7.5-10.7)\end{array}$ & $\begin{array}{c}4.4 \\
(3.6-5.1)\end{array}$ & $\begin{array}{c}2.0 \\
(1.8-2.3)\end{array}$ & $\begin{array}{c}11.1 \\
(8.0-13.2)\end{array}$ \\
\hline \multicolumn{5}{|l|}{ Liver } \\
\hline Control $(n=6)$ & $\begin{array}{c}262.3 \\
(202.6-291.5) \\
\end{array}$ & $\begin{array}{c}128.5 \\
(90.7-148.1 \\
\end{array}$ & $\begin{array}{c}2.1 \\
(1.9-2.3) \\
\end{array}$ & $\begin{array}{c}252.2 \\
(139.2-317.6) \\
\end{array}$ \\
\hline
\end{tabular}

* Thiolase activity is expressed as nmol of substrate decreased/min/ mg protein. Father 1 and Mother 1 are the father and mother of GK01, respectively. 


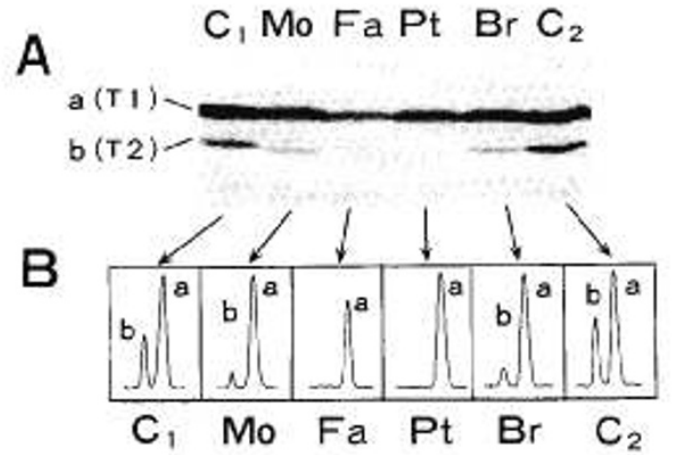

Fig. 1. Immunoblot analysis of $\mathrm{T} 1$ and $\mathrm{T} 2$ in fibroblasts of family 2 . Panel $A$, immunoblot using a mixture of anti-T 1 and anti-T2 antibodies; panel $B$, peaks of the bands for T1 and T2 obtained by densitometry. $C_{1}$ and $C_{2}$, normal controls; $M O$, the mother of GK04; $\mathrm{Fa}$, the father of GK04; $P t$, GK04; $B r$, the brother of GK04. In panel $B$, peaks $a$ and $b$ represent bands for $\mathrm{T} 1$ and $\mathrm{T} 2$, respectively.

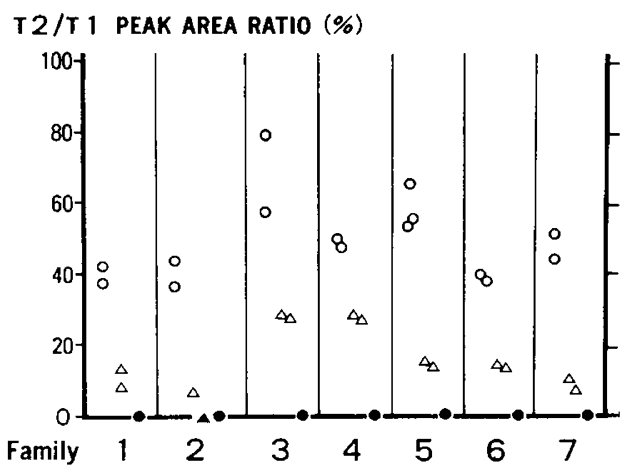

Fig. 2. The ratio of peak areas of the two bands for T2 and T1 (T2/ $T 1$ ratio) determined by densitometry. $O$, Normal controls; $\Delta$, the parents, obligate carriers; $\boldsymbol{\bullet}$, 3KTD patients; $\mathbf{\Lambda}$, the father of GK04, who is affected. Immunoblotting was performed independently in each column.

GK04, GK05, the mother, and the brother of GK04 of family 2 . Densitometric tracings of these blots are shown in Figure $1 B$. No T2 band was detectable in either GK04 or GK05 (indicated as $P t$ and $F a$, respectively in Fig. $1 A$ ). A faint $\mathrm{T} 2$ band was detectable in the blot from the mother and the brother (lanes $\mathrm{Mo}$ and $\mathrm{Br}$, respectively). In contrast, the $\mathrm{T} 1$ band was clearly detectable in all lanes. Peak $b$ was undetectable for both GK04 and GK05. Although peak $b$ is present in the blot from the mother and the brother, its intensity was much weaker than in controls.

Immunoblot analysis for $\mathrm{T} 2$ and $\mathrm{T} 1$ proteins were further carried out on the cultured fibroblasts from six additional families with $3 \mathrm{KTD}$, followed by densitometry. We found that the $\mathrm{T} 2 / \mathrm{T} 1$ ratio was zero in all eight index patients. Among their parents, $\mathrm{T} 2$ was detectable, but the $\mathrm{T} 2 / \mathrm{T} 1$ ratio was markedly lower than in controls (Fig. 2). No overlap of the T2/T1 ratio was observed between controls and obligate carriers of 3KTD.

Immunoblot detection of thiolases in various human tissues. Figure $3 A$ shows immunoblots of $\mathrm{T} 1$ and $\mathrm{T} 2$ in amniocytes, lymphocytes, rectal mucosa, and human liver and fibroblasts from the normal controls. $\mathrm{T} 1$ and $\mathrm{T} 2$ bands were evident in all these specimens. In immunoblots of $\mathrm{T} 1$ and $\mathrm{T} 2$ in lymphocytes, the intensity of the T1 band was essentially the same in one patient (GK01), his parents, and normal controls, whereas no $\mathrm{T} 2$ band and only a faint T2 band were detectable in cells from GK01 and in cells from his parents, respectively (Fig. $3 B$ ). Figure $3 C$ shows immunoblots of $\mathrm{T} 1$ and $\mathrm{T} 2$ in rectal mucosa from GK01 and normal controls. In the patient's specimen, a T1 band was detected but a T2 band was not, whereas both bands were clearly visible in controls.
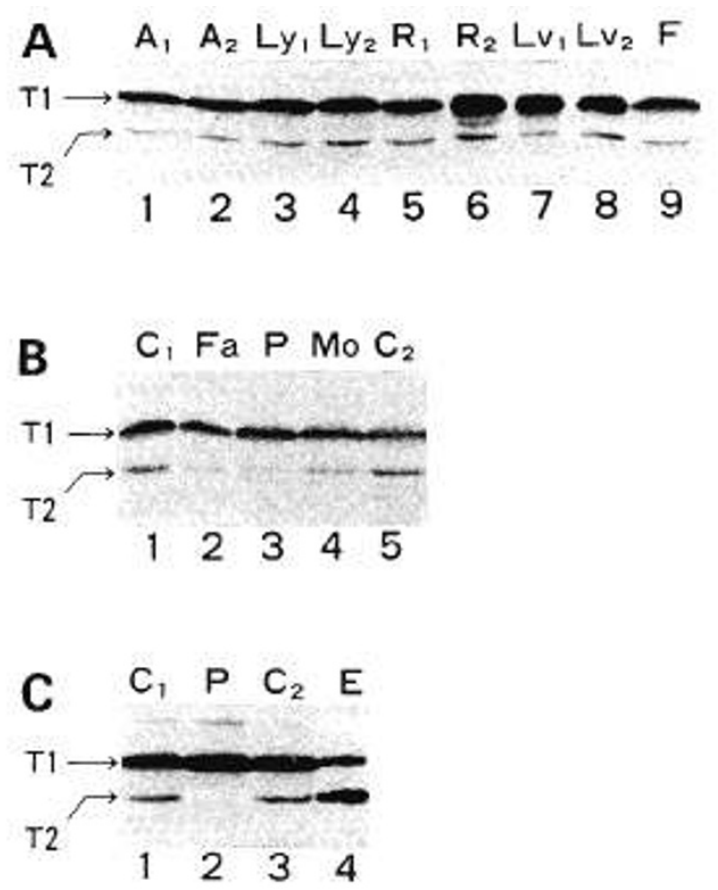

Fig. 3. Immunoblots of $\mathrm{T} 1$ and $\mathrm{T} 2$ in various human tissues. Panel $A$, immunoblots in tissues from normal individuals; panel $B$ immunoblots in lymphocytes from family 1 ; panel $C$, immunoblots in rectal mucosa from GK01. $A_{1}$ and $A_{2}$, amniocytes from normal controls; $L y_{1}$ and $L y_{2}$, lymphocytes from controls; $R_{1}$ and $R_{2}$, rectal mucosa from controls; $L v_{1}$ and $L v_{2}$, liver from controls; $F$, fibroblasts from a control; $C_{1}$ and $C_{2}$, tissues from normal controls; $P, \mathrm{GK} 01 ; F a$ and $M o$, the father and mother of GK01, respectively; and $E$, purified human thiolases, T1 and T2 (5 ng each of protein applied).

\section{DISCUSSION}

The enzymatic diagnosis of 3KTD is based on either the lack of increase in acetoacetyl-CoA thiolase activity with the addition of $\mathrm{K}^{+}$ion $(10)$ or the absence of thiolase activity when 2methylacetoacetyl-CoA was used as substrate (2). In this study, we have shown that the measurement of the $\mathrm{K}+/ \mathrm{K}$ - ratio of acetoacetyl-CoA thiolase activities in fibroblasts or lymphocytes appeared to be useful in identifying heterozygotes for $3 \mathrm{KTD}$, but a small overlap of the values between normal controls and heterozygotes occurred. Middleton (23) previously determined T2 activity in eight cases of 3KTD obligate heterozygotes using 2-methylacetoacetyl-CoA as substrate. He reported that values in most of the heterozygotes were distinctly lower than in controls, but here, too, some overlaps between controls and heterozygotes occurred.

We have shown here that the immunoblot determination of the $\mathrm{T} 2 / \mathrm{T} 1$ ratio is a more reliable method for the identification of homozygotes and heterozygotes of $3 \mathrm{KTD}$. We previously experienced difficulty in identifying heterozygotes by immunoblot analysis using anti-T2 antibody alone (11). However, such ambiguity of the results was completely eliminated by the combined use of anti-T1 antibody. The intensity of the T2 band can be assessed more accurately by comparing it with that of the T1 band. With this method, heterozygotes may be easily identified by only visual assessment of the immunoblots in many cases. It is possible that this method cannot be used for mutants that produce a stable variant $\mathrm{T} 2$ in an amount that is comparable to that of controls. However, such a case has not been found among $153 \mathrm{KTD}$ patients that we have examined so far (13). Hence, this method should be useful for most families with 3KTD. Because the number of families examined in this study is still small, it is important in the future to study the index cases in each family before attempting carrier detection or prenatal diagnosis. Immunoblotting requires a smaller number of cells and 
may provide more rapid and reliable results than enzyme assay (24).

The finding that $\mathrm{T} 2$ is likely to be expressed in every human tissue may agree with the findings that the T2 gene has the features that are characteristic of housekeeping genes (25). Peripheral lymphocytes or rectal mucosa are useful for the assay of the activity or the immunoblot analysis of the thiolases. The specific activities in these tissues are higher than in fibroblasts. Unlike cultured skin fibroblasts, the results may be readily obtainable using these tissues. In a preliminary experiment, we also detected T2 protein in chorionic villi from a normal individual (data not shown). Thus, these findings suggest that it is possible to perform prenatal diagnosis of this disease using amniocytes or chorionic villi.

Acknowledgment. The authors thank M. Ohara for helpful comments and Prof. K. Tanaka, Department of Genetics, Yale University, for constructive discussion on this study.

\section{REFERENCES}

1. Daum RS, Scriver CR, Mamer OA, Devlin E, Lamm P, Goldman H 1973 An inherited disorder of isoleucine catabolism causing accumulation of $\alpha$ methylacetoacetate and $\alpha$-methyl- $\beta$-hydroxybutyrate, and intermittent metabolic acidosis. Pediatr Res 7:149-160

2. Middleton B, Bartlett K 1983 The synthesis and characterization of 2-methylacetoacetyl coenzyme $A$ and its use in the identification of the site of the defect in 2-methylacetoacetic and 2-methyl-3-hydroxybutyric aciduria. Clin Chim Acta 128:291-305

3. Sweetman L 1989 Branched chain organic acidurias. In: Scriver CR, Beaudet AL, Sly WS, Valle D (eds) The Metabolic Basis of Inherited Metabolic Disease. McGraw-Hill, New York, pp 791-819

4. Yamaguchi S, Orii T, Sakura N, Miyazawa S, Hashimoto T 1988 Defect in biosynthesis of mitochondrial acetoacetyl-coenzyme A thiolase in cultured fibroblasts from a boy with 3-ketothiolase deficiency. J Clin Invest 81:813817

5. Middleton B, Bartlett K, Romanos A, Gomez Vazquez J, Conde C, Cannon RA, Lipson M, Sweetman L, Nyhan WL 1986 3-Ketothiolase deficiency. Eur J Pediatr 144:586-589

6. Leonard JV, Middleton B, Seakins JWT 1987 Acetoacetyl CoA thiolase deficiency presenting as ketotic hypoglycemia. Pediatr Res 21:211-213

7. Miyazawa S, Osumi T, Hashimoto T 1980 The presence of a new 3-oxoacylCoA thiolase in rat liver peroxisomes. Eur J Biochem 103:589-596

8. Uchida $Y$, Izai $K$, Orii T, Hashimoto T 1992 Novel fatty acid $\beta$-oxidation enzymes in rat liver mitochondria. J Biol Chem 267:1034-1041

9. Middleton B 1973 The oxoacyl-coenzyme-A thiolase in animal tissues. Biochem J 132:717-730

10. Robinson BH, Sherwood WG, Taylor J, Balfe JW, Mamer OA 1979 Acetoacetyl-CoA thiolase deficiency. A cause of severe ketoacidosis in infancy simulating salicylism. J Pediatr 95:228-233

11. Nagasawa H, Yamaguchi S, Orii $T$, Schutgens RBH, Sweetman L, Hashimoto
T 1989 Heterogeneity of defects in mitochondrial acetoacetyl-CoA thiolase biosynthesis in fibroblasts from four patients with 3-ketothiolase deficiency. Pediatr Res 26:145-149

12. Yamaguchi S, Fukao T, Nagasawa H, Orii T, Sakura N, Schutgens RBH Sweetman L, Fujiki Y, Kamijo K, Osumi T, Hashimoto T 1990 3-Ketothiolase deficiency: molecular heterogeneity of the enzyme defect and cloning of the cDNA. In: Tanaka K, Coates P (eds) Fatty Acid Oxidation: Clinical, Biochemical, and Molecular Aspects, Alan R Liss, Inc, New York, pp 673679

13. Fukao T, Yamaguchi S, Orii T, Osumi T, Hashimoto T 1992 Molecular basis of 3-ketothiolase deficiency. In: Tanaka K, Coates P (eds) New Developments in Fatty Acid Oxidation, Alan R Liss, Inc, New York, pp 573-581

14. Fukao T, Yamaguchi S, Kano M, Orii T, Fujiki Y, Osumi T, Hashimoto T 1990 Molecular cloning and sequence of the complementary DNA encoding human mitochondrial acetoacetyl-coenzyme $A$ thiolase and study of the variant enzymes in cultured fibroblasts from patients with 3-ketothiolase deficiency. J Clin Invest 86:2086-2092

15. Fukao T, Yamaguchi S, Tomatsu S, Orii T, Frauendienst-Egger G, Schrod L, Osumi T, Hashimoto T 1991 Evidence for a structural mutation (347Ala to Thr) in a German family with 3-ketothiolase deficiency. Biochem Biophys Res Commun 179:124-129

16. Fukao T, Yamaguchi S, Orii T, Osumi T, Hashimoto T 1992 Molecular basis of 3-ketothiolase deficiency: identification of an AG to AC substitution at the splice acceptor site of intron 10 causing exon 11 skipping. Biochim Biophys Acta 1139:184-188

17. Fukao T, Yamaguchi S, Orii T, Schutgens RBH, Osumi T, Hashimoto T 1992 Identification of three mutant alleles of the gene for mitochondrial acetoacetyl-coenzyme A thiolase: complete analysis of a family with 3-ketothiolase deficiency in two generations. J Clin Invest 89:474-479

18. Fukao T, Yamaguchi S, Wakazono A, Okamoto H, Orii T, Osumi T, Hashimoto T 1992 Molecular basis of 3-ketothiolase deficiency: detection of gene mutation and expression of mutant cDNAs of mitochondrial acetoacetylCoA thiolase. J Inherited Metab Dis 15:815-820

19. Wajner M, Paim MT, Giugliani R, Sweetman L, Yamaguchi S, Fukao T, Shih VE 1992 Biochemical investigation of a Brazilian patient with a defect in mitochondrial acetoacetyl-coenzyme A thiolase. Clin Genet 41:202-205

20. Yamaguchi S, Fukao T, Kano M, Wakazono A, Orii T, Sakura N, Hashimoto $\mathrm{T} 1992$ Further analysis of mutant thiolase protein in fibroblasts from a Japanese boy with 3-ketothiolase deficiency. Tohoku J Exp Med 167:143153

21. Hiyama K, Sakura N, Matsumoto T, Kuhara T 1986 Deficient beta-ketothiolase activity in leukocytes from a patient with 2-methylacetoacetic aciduria. Clin Chim Acta 155:189-194

22. Schutgens, RBH, Middleton B, Blij JF, Oorthuys WE, Veder HA, Vulsma T, Tegelaers WHH 1982 Beta-ketothiolase deficiency in a family confirmed by in vitro enzymatic assays in fibroblasts. Eur J Pediatr 139:39-42

23. Middleton B 1987 Identification of heterozygotes for the defect of mitochondrial 3-ketoacyl-CoA thiolase causing 2-methyl-3-hydroxybutyric aciduria. J Inherited Met Dis 10(suppl 2):270-272

24. Yamaguchi S, Shimizu N, Orii T, Fukao T, Suzuki Y, Maeda K, Hashimoto T, Previs SF, Rinaldo P 1991 Prenatal diagnosis and neonatal monitoring of a fetus with glutaric aciduria type II due to electron transfer flavoprotein ( $\beta$-subunit) deficiency. Pediatr Res 30:439-443

25. Kano M, Fukao T, Yamaguchi S, Orii T, Osumi T, Hashimoto T 1991 Structure and expression of the human mitochondrial acetoacetyl-CoA thiolase-encoding gene. Gene 109:291-305 